Artigos

Volume 10 - $2020 \mid$ n. 4

\title{
Aspectos da Sociodinâmica Público e Privado na Política de Educação Especial no Estado do Espírito Santo
}

\author{
Gildásio Macedo de Oliveira \\ Reginaldo Célio Sobrinho \\ Universidade Federal do Espírito Santo (UFES), Vitória/ES - Brasil
}

\section{Resumo $^{1}$}

Neste artigo problematizamos aspectos dos fins políticos e sociais relativos à contratação do Atendimento Educacional Especializado privado, feita pelo governo do estado do Espírito Santo (BRA). Reunimos dados das despesas efetuadas pela administração pública nos anos de 2014 (início do modelo de contratação) e de 2017. Esses dados foram extraídos do portal da transparência do governo estadual e das planilhas de filtragem do Fundeb. Observamos que, na disputa pelo fundo público, parte considerável dos recursos da Educação Especial é destinada à iniciativa privada. Registramos a necessidade de aprimoramento na transparência das despesas públicas relativas à terceirização dos serviços educacionais, a fim de enrijecer as fronteiras entre o público e privado, bem como potencializar o controle social sobre a materialização do direito à educação.

Palavras-chave: Educação Especial. Política Educacional. Privatização. Financiamento.

\section{Aspects of Public and Private Sociodynamics in the Special Education Policy in the State of Espírito Santo}

\begin{abstract}
In this article, we discuss aspects of the political and social purposes related to the contracting of private Specialized Educational Service, made by the state of Espírito Santo, Brazil. We collected data on expenditures made by the public administration in 2014 (at the beginning of the contracting model) and in 2017. These data were extracted from the state government's transparency portal and Fundeb's filtering worksheets. We have noticed that, in the fight for the public fund, a considerable part of the resources of Special Education is aimed to the private sector. We also observed the need to improve the transparency of public expenditures related to the outsourcing of educational services, in order to strengthen the boundaries between the public and private sectors, as well as to strengthen social control over the achievement of the right to education.
\end{abstract}

Keywords: Special Education. Educational Policy. Privatization. Funding.

1 Trabalho desenvolvido com o apoio da Fundação de Amparo à Pesquisa do Estado do Espírito Santo (Fapes). 
Aspectos da Sociodinâmica Público e Privado na Política de Educação Especial no Estado do Espírito Santo

\section{Introdução}

Tomando como perspectiva de análise os constructos da sociologia figuracional, elaborada por Norbert Elias (1994), assumimos a compreensão de que as políticas públicas não são, de maneira alguma, o resultado da vontade de uma pessoa isolada ou de um conjunto delas num vácuo social. Elas se constituem num jogo inter-relacional e processual, cuja dinâmica se refere à contínua distribuição de chances de poder entre indivíduos e grupos envolvidos direta e/ou indiretamente na sua elaboração e na sua materialização. Assim é que, para nós, as políticas públicas não devem ser interpretadas como ação concatenada de atos sucessórios previamente planejados, nos quais as pessoas se apresentam, tão somente, como meras expectadoras da história em curso. Fundamentados nos constructos eliasianos, compreendemos que as políticas públicas têm seus sentidos e sua direção constituídos pelas singularidades vividas nas teias de relações humanas que, marcadas por um contínuo equilíbrio de tensões, abrem fissuras e estabelecem caos, significando e legitimando (provisoriamente) as transformações e mudanças sociais. As políticas públicas se configuram, então, como uma arena de disputas e de negociação permanente entre indivíduos e grupos, independentemente das posições sociais ocupadas por eles, seja na condição de governantes, ou de governados.

No âmbito do grupo de pesquisa "Políticas, Gestão e Inclusão Escolar: contextos e processos sociais" desenvolvemos estudos relativos à materialização das políticas educacionais em realidades latino-americanas, especialmente no Brasil e no México. Articuladas a essas questões que viemos estudando ${ }^{2}$, neste texto, sistematizamos reflexões objetivando problematizar aspectos dos fins políticos e sociais relativos à contratação do Atendimento Educacional Especializado privado, feita pelo governo do estado do Espírito Santo (BRA). No cumprimento desse propósito, realizamos análise documental com base em dados de fontes primárias extraídos do portal da transparência do governo do estado do Espírito Santo e das planilhas de filtragem do Fundeb. Dessa forma, reunimos dados concernentes às despesas efetuadas pela administração pública no ano de 2014 (início do modelo de contratação desse serviço) e as despesas efetuadas no ano de 2017.

Perspectivando que as políticas de Educação Especial se constituem como processo e resultado de disputas sociais vividas historicamente, na primeira parte deste texto apresentamos algumas notas sobre a Educação Especial no Brasil, a fim de levantarmos balizas substantivas que instrumentalizem a discussão que nos propusemos desenvolver. $\mathrm{Na}$ sequência, visando compreender os aspectos políticos e econômicos que delineiam as políticas de educação especial, apresentamos a categoria privatização da e na educação problematizando o "lugar" de realização do Atendimento Educacional Especializado (AEE). Finalmente, trazemos para a análise os dados empíricos que expressam a política recentemente adotada na gestão pública da rede de ensino estadual, no intuito de pontuar considerações sobre fins políticos e sociais da política em curso no Espírito Santo (BRA).

2 Projeto de pesquisa intitulado: "Política orçamentária e trabalho docente na Educação Especial em realidades brasileira e mexicanas" (CNPq). 
Aspectos da Sociodinâmica Público e Privado na Política de Educação Especial no Estado do Espírito Santo

\section{Notas Sobre a Educação Especial no Brasil: política e processos sociais}

No curso do século XX o caráter caritativo e assistencialista das Instituições Especializadas em Educação Especial ganhou significativo destaque no cenário nacional, principalmente devido ao vácuo deixado pelo Estado em relação à proposição de políticas sociais profícuas para essas pessoas (MAZZOTTA, 2011; JANNUZZI, 2015). Emerge assim a ênfase, que permanece até os dias atuais, da necessidade de um caráter fortemente protetivo para esse público. Não sem razão, no início do século $X X$, sob o viés caritativo, as escolas especiais, representadas principalmente pela Associação Pestalozzi e pela Associação de Pais e Amigos dos Excepcionais (Apae), conseguiram se estabelecer em redes paralelas ao ensino público, contando inclusive com incentivo financeiro governamental (MAIOR, 2017).

Mazzotta (2011, p. 47), nos esclarece que desde a criação da primeira Apae, em 1954, "[...] o movimento se espalhou pelo território nacional e, atualmente, conta com uma [...] importante Federação Nacional das APAES, com mais de mil entidades associadas". Essa vertiginosa expansão ${ }^{3}$ pode ser atribuída, sobretudo, à concepção caritativa adotada oficialmente pelo governo brasileiro.

A década de 1980 foi marcada por diferentes diretrizes internacionais estabelecidas pela Organização das Nações Unidas (ONU). O ano de 1981, por exemplo, foi instituído como o "Ano Internacional das Pessoas Deficientes" (AIPD). Esse marco histórico "[...] colocou as pessoas com deficiência no centro das discussões, no mundo e também no Brasil" (LANNA JUNIOR, 2010, p. 37).

Nesse diapasão, entendemos que esse movimento coloca na pauta oficial a diferença como categoria intrinsecamente humana. De fato, a partir do estímulo do AIPD,

[...] o movimento das pessoas com deficiência conseguiu com que as questões antes, historicamente ligadas à religião ou à medicina, fossem, enfim, deslocadas para o campo das Ciências Sociais e dos Direitos Humanos (SÃO PAULO, 2011, p. 14, grifo nosso).

Ainda no final da década de 1980, a Constituição da República Federativa do Brasil (CRFB) contemplou esse deslocamento ao estabelecer no título VIII (que trata da Ordem Social Nacional) significativos direcionamentos para todo ordenamento nacional. Por essa via foi reconhecido constitucionalmente que as pessoas com deficiência são sujeitos de direitos. Cabe ressaltar que a Ordem Social dita o conjunto de preceitos para implementação dos direitos sociais previstos no artigo $6^{\circ}$ da Constituição ${ }^{4}$ (BULOS, 2015). Particularmente, no caso da educação, encontra-se no artigo 208, inciso III, a opção do Estado brasileiro pelo Atendimento Educação Especializado (AEE) preferencialmente na rede regular de ensino como principal estratégia para garantir o direito público subjetivo da educação para as pessoas com deficiência.

$\mathrm{Na}$ mesma direção, a Constituição Estadual do Espírito Santo, embebecida pelo pensamento da fragmentação do ensino, também disciplinou que:

Há atualmente 2.178 unidades associadas presentes em todo o território nacional, tendo como público pessoas com deficiência intelectual e múltipla (Disponível em: <https://apaebrasil.org.br/page/2>).

4 Art. $6^{\circ}$ São direitos sociais a educação, a saúde, a alimentação, o trabalho, a moradia, o transporte, o lazer, a segurança, a previdência social, a proteção à maternidade e à infância, a assistência aos desamparados, na forma desta Constituição. 
Aspectos da Sociodinâmica Público e Privado na Política de Educação Especial no Estado do Espírito Santo

Art. 171. Constitui obrigação dos Poderes Públicos:

I - a garantia de educação especial, até a idade de dezoito anos em classes especiais, para a pessoa com deficiência que efetivamente não possa acompanhar as classes regulares;

$[\ldots]$

IV - a manutenção e conservação dos estabelecimentos públicos de ensino. Parágrafo único. O Estado aplicará na Educação Especial destinada à pessoa com deficiência percentual dos recursos disponíveis para a educação (ESPÍRITO SANTO, 1989, art. 171).

Ainda assim, com a CFRB/1988 (BRASIL, 1988), o Estado brasileiro passou a exercer o monopólio de Educação de forma mitigada, haja vista que contemplou o ensino à livre iniciativa privada (art. 209), e "[...] o seu artigo 213 abriu brecha para utilização dos recursos públicos no setor privado, restringindo tal uso em entidades privadas sem fins lucrativos, de caráter filantrópico, confessional e comunitário" (ARAÚJO, 2017, p. 10).

Mais tarde, a Lei 9.394/96 (BRASIL, 1996), que estabelece as Diretrizes e Bases da Educação Nacional, trouxe em sua redação o reforço da possibilidade de escoamento dos recursos públicos para a Educação Especial ofertada por instituições especializadas de natureza privada. Destaca-se que o legislador deixou a critério dos órgãos normativos a caracterização das instituições privadas sem fins lucrativos que, eventualmente, viessem a receber apoio técnico e financeiro pelo poder Público.

Art. 60. Os órgãos normativos dos sistemas de ensino estabelecerão critérios de caracterização das instituições privadas sem fins lucrativos, especializadas e com atuação exclusiva em educação especial, para fins de apoio técnico e financeiro pelo Poder Público.

Parágrafo único. O poder público adotará, como alternativa preferencial, a ampliação do atendimento aos educandos com deficiência, transtornos globais do desenvolvimento e altas habilidades ou superdotação na própria rede pública regular de ensino, independentemente do apoio às instituições previstas neste artigo (BRASIL, 1996, art. 60 , grifo nosso).

Avaliando o teor normativo trazido na LDB, Araújo (2015, p. 3), pontua que:

[...] a redação desta lei é por demais maleável e ambígua, permitindo que no decorrer de sua vigência as instituições privadas fossem se adaptando a suas regras com o intuito de se habilitar a receber recursos públicos.

Ou seja, ao mesmo tempo em que se busca garantir o direito da pessoa com deficiência à oferta de Educação Especial na rede pública de educação, o texto legal acentua o compromisso do Estado em oferecer a Educação Especial, com ênfase no apoio técnico e financeiro às instituições privadas sem fins lucrativos (VIEGAS; BASSI, 2009).

Nos anos recentes, ao buscar instituir políticas públicas para as pessoas com deficiência, o Estado brasileiro disparou várias iniciativas importantes: obrigatoriedade de constituição de um setor responsável pela Educação Especial em todos os sistemas de ensino, dotado de recursos humanos, materiais e financeiros - Resolução $n^{\circ}$ 02/2001 (BRASIL, 2001) do Conselho Nacional de Educação (CNE); organização do AEE para as pessoas com deficiência em salas de recursos das escolas comuns ou Centros de Atendimento Educacional Especializado (CAEE) públicos ou privados - Resolução n 4/2009 (BRASIL, 2009) do CNE. Além de responder às indicações expressas nessas resoluções, 
Aspectos da Sociodinâmica Público e Privado na Política de Educação Especial no Estado do Espírito Santo

consoante ao que estabelecem o artigo 60 da LDBEN 9.394/1996 (BRASIL, 1996) e a Resolução n 4/2009 (BRASIL, 2009), no Espírito Santo, o Conselho Estadual de Educação (CEE), por meio da resolução $n^{\circ} 2.152 / 2010$ (ESPÍRITO SANTO, 2010), disciplinou normas para regulação da relação entre instituições comunitárias, confessionais ou filantrópicas sem fins lucrativos e o poder público. Disciplinado, assim, a oferta de atendimento de cunho estritamente educacional em seus CAEEs ${ }^{5}$.

Recentemente, o CEE, por meio da Resolução 3.777 de 2014, alçou o AEE como um dos princípios norteadores da Educação Especial (ESPÍRITO SANTO, 2014b). Tal iniciativa é desdobramento direto da Política Nacional de Educação Especial na Perspectiva da Educação Inclusiva (BRASIL, 2008) que colocou formalmente o Brasil no rumo da educação inclusiva. Conceitualmente, a perspectiva inclusiva se define como "[...] uma ação política, cultural, social e pedagógica, desencadeada em defesa do direito de todos os estudantes de estarem juntos, aprendendo e participando, sem nenhum tipo de discriminação" (BRASIL, 2008). Sem perder de vista esse cenário político, no próximo item focalizaremos aspectos da dinâmica social que justifica e acentua o processo de privatização da e na educação Especial.

\section{Atendimento Educação Especializado (AEE): a privatização da e na educação especial}

As questões trazidas anteriormente nos provocaram algumas indagações: Como se encontra atualmente o financiamento da Educação Especial na rede pública estadual de ensino no Espírito Santo? Como a dinâmica da privatização vem atuando nessa modalidade de ensino?

Como importante especialista da área, Garcia (2016) aponta que as reformas educacionais em curso difundem a lógica mercadológica ao fomentar o discurso de que o setor privado é mais eficiente do que o setor público. Alinhados com a autora, entendemos que essa estratégia silencia e negligencia importantes aspectos relativos à precarização do/no trabalho docente na escola pública. E isso se faz em decorrência de certo afrouxamento nas fronteiras entre o público e o privado, sobretudo quando da apropriação do fundo público.

De acordo com Ball e Youdell (2008) existem dois tipos principais de privatização que se operam no campo educacional, a endógena - que importa ideias e práticas do setor privado na intenção de tornar o ensino um balcão de negócio - e a exógena - que torna franca a destinação de recursos públicos ao setor privado no tocante a sua participação direta na prestação de serviços/atividades ofertadas pela administração pública. Nessa perspectiva, Garcia (2016) compreende a privatização da educação (indireta - endógena) e na educação (direta - exógena) como uma característica das políticas educacionais que o Estado brasileiro vem, crescentemente, implementando.

No debate que nos propusemos desenvolver neste texto, as indicações de Garcia (2016) são extremamente adequadas, principalmente quando considera que nas políticas de

5 Em 2013, por meio da nota técnica n 55 de 10/05/2013 (BRASIL, 2013), o MEC estabeleceu o entendimento de que as escolas especiais poderiam transformar-se em Centros de Atendimento Educacional Especializado, colaborando na construção de um sistema educacional inclusivo. Assim, no Estado do Espírito Santo, desde 2014, o AEE ofertado pelos Centros de Atendimento Educacional Especializado (CAEEs) no turno contrário ao da escolarização vem sendo considerado, oficialmente, como um serviço, com valor estabelecido em $\mathrm{R} \$ 325,77$ (trezentos e vinte e cinco reais e setenta e sete centavos) por aluno/mês, escancarando de vez a disputa pelo fundo público, ao arrepio da legislação pátria (ESPÍRITO SANTO, 2014a). 
Aspectos da Sociodinâmica Público e Privado na Política de Educação Especial no Estado do Espírito Santo

Educação especial adotadas a ampliação da atuação do setor privado se evidencia em duas vias, a saber:

[...] a) com a participação do privado-mercantil mediante a venda de equipamentos para as salas de recursos multifuncionais; e b) frente à não universalização do atendimento educacional especializado, nas redes públicas, destaca-se a participação do privadoassistencial nessa oferta mediante conveniamentos das redes de ensino com instituições filantrópicas (GARCIA, 2016, p. 12, grifo nosso).

Nesse debate, cabe sublinhar que com o Fundo de Manutenção e Desenvolvimento da Educação Básica e de Valorização dos Profissionais da Educação (Fundeb), em vigor desde 2007 (e com previsão de término em 2020), houve maior estímulo financeiro para que redes públicas promovessem a expansão da matrícula (VIEGAS; BASSI, 2009). A lei no 11.494, de 20 de junho de 2007 (BRASIL, 2007), que regulamentou o Fundeb, novamente repisou que para receber financiamento público as instituições filantrópicas de natureza privada deveriam garantir, necessariamente, entre outros critérios, a igualdade de condições para o acesso e a permanência na escola e o atendimento educacional gratuito a todos os seus alunos (BRASIL, 2007). Outro ponto importante dessa lei foi a instituição da dupla matrícula para os alunos público-alvo da Educação Especial com matrícula na rede pública e que recebem atendimento educacional especializado (seja na própria rede pública ou seja em Instituições sem fins lucrativos conveniadas com o poder público).

Na reflexão sobre esse duplo financiamento, vale considerar o AEE como um importante componente para o acesso, a permanência e a aprendizagem com qualidade para as pessoas com deficiência na escola comum. É imperioso destacar que esse atendimento não deve ser visto como um mero serviço e muito menos algo deslocado do ensino comum. Assim, compartilhamos o entendimento de Baptista (2011), que compreende esse "apoio" como direito dos estudantes com deficiência, em um sentido mais amplo, ou seja, como um processo de diálogo multidimensional que perpassa tanto o acompanhamento dos processos pedagógicos que ocorrem nas salas de aula de ensino comum, passando pelo acesso necessário ao currículo, e pela articulação com os familiares ou outros profissionais que têm trabalhado com os alunos (BAPTISTA, 2011).

Por esse balizamento é que, na nossa percepção, a ampliação da oferta do AEE na rede pública é a ação mais sensata, pois tem a alçada de materializar o preceito constitucional de educação com qualidade para todos, rechaçando qualquer mecanismo que venha a diminuir o escopo educacional que traga à tona preceitos já ultrapassados, tais como provisoriedade, excepcionalidade, segregação ou exclusão.

Portanto, tudo que foge a essa premissa, ao nosso ver, afronta os princípios normativos legais no Estado democrático de direito; e, não é demais considerar, caracteriza forte evidência de apropriação dos recursos públicos pelo setor privado (OLIVEIRA, 2016). Melhor dizendo, alinhados a Garcia (2016), entendemos que a não universalização do AEE nas redes públicas é uma forma explícita de privatização da modalidade da educação especial, na medida em que concede a terceiros a oferta dessa atividade, que é essencial para garantia do direito à aprendizagem das pessoas com deficiência na escola comum.

Reiteramos que a realização descontextualizada do AEE em relação ao cotidiano escolar concorre de maneira direta para o aumento da distância entre o aluno com deficiência e os objetos de conhecimento e o direto de aprender, mesmo diante da obrigatoriedade de 
Aspectos da Sociodinâmica Público e Privado na Política de Educação Especial no Estado do Espírito Santo

matrícula na escola pública. É importante considerar que a garantia da matrícula na escola de ensino comum não é suficiente para que ocorra o processo de aprendizagem de forma dialógica e multidimensional com os apoios ofertados para esse público específico.

Fundamentados nessa observação, compreendemos que a não universalização do AEE nas redes públicas caracteriza-se também como uma forma de privatização na educação. Por essa via, o Estado corrobora a perspectiva de que o setor privado é mais eficiente que o público, abrindo mão de seu aparato público que, indiscutivelmente, tem maior capacidade de alcance aos destinatários da política pública - os alunos com deficiência.

É nesse sentido que, para nós, a primazia da oferta do AEE na própria rede pública de ensino é a melhor interpretação técnica. Ocorre que no cenário dessa discussão emerge outra importante questão. Trata-se do argumento apresentado pelas Instituições Especializadas referente à lesão ao direito de "possibilidade de escolha da família". Na nossa compreensão, esse argumento tem servido mais para acirrar a disputa pelo fundo público, trazendo inspirações mercadológicas em um debate que a própria natureza jurídica não comporta, ou pelo menos não deveria comportar. Nessa linha, Adrião e Garcia (2018) entendem que a escolhas parentais podem subsidiar as desigualdades sociais e educativas, subordinando a oferta da educação básica a interesses privados que, via de regra, extrapolam as expectativas expressas pelas famílias. No mesmo diapasão, Nóvoa (2002, p. 11-12) explica que a questão da "propriedade" dos estabelecimentos de ensino é indiferente. O que deve ser pautado é a diferença entre "[...] perspectivas que organizam a educação numa esfera privada ou numa esfera pública". O autor defende a garantia do espaço público da educação, pois o

[...] nosso drama nunca foi 'educação a mais', mas sim 'educação a menos'; [...] Ao modelo de a cada um a sua escola, à perspectiva de uma educação que tende a 'fechar' as crianças nos seus meios sociais e nas suas culturas de origem [...] (NÓVOA, 2002, p. 15).

O argumento de "escolha" parental não potencializa a dinâmica formativa dos alunos principais interessados -, mas ao contrário, os recoloca dentro da "caverna", com a propensão de fechá-los em si mesmos. Essa estratégia não coaduna com a escola como "[...] um espaço público democrático e participado, no quadro de redes de comunicação e de cultura, de arte e de ciência" (NÓVOA, 2002, p. 17). Nessa mesma linha, concordamos com Apple (2001, p. 19), quando assevera que "[...] definir todos como consumidores e a democracia como uma escolha individual de consumo é um projeto radicalmente individualizador com um conjunto de identidades a si agregadas radicalmente individualizadas". Evidente que não se trata de afastar a família da educação de seus filhos. Ao contrário, acreditamos na potencialização da diversidade em que a escola para todos seja construída e repensada com todos conforme as especificidades do conjunto e não idealizada para alguns.

Ainda assim, vale destacar que uma das características das políticas de Educação Especial que se mantém no decorrer de muitos anos é a transferência da responsabilidade da educação dos estudantes com deficiência para as Instituições Especializadas privadas sem fins lucrativos - fato que gera a estagnação da ampliação do atendimento nas escolas públicas comuns (MORAES, 2011; PEREIRA, 2012; BOROWSKY, 2013; SOTO et al., 2012; FRANÇA, 2015; PANTALEÃO; SOBRINHO 2011). Todavia, percebe-se que essa transferência não é feita de forma harmoniosa, pois é resultado de relações humanas interdependentes e com perspectivas ora divergentes, ora convergentes. Cabe, portanto, evitar a esparrela da transposição direta de méritos do livre-mercado para a Administração 
Aspectos da Sociodinâmica Público e Privado na Política de Educação Especial no Estado do Espírito Santo

Pública. Haja vista que os preceitos públicos visam à garantia de direitos sociais sensíveis e amplos.

Nesse debate, concordamos com Adrião (2018), quando afirma que relações não horizontais acobertam a subordinação formal e concreta ao setor privado. Ao mitigar investimento necessário à complexidade da educação com ênfase na sociedade plural, pavimenta-se, tão somente, o cenário para criação e/ou confirmação de espaços alternativos de convivência conformado ao escopo da racionalidade técnica, pilar fundamental do sistema produtivo capitalista.

\section{Fundeb - A Educação Especial como esforço estatal}

O Fundeb estabeleceu um valor mínimo nacional por matrícula, estipulado a cada ano, em função da estimativa de arrecadação de impostos e contribuições que constituem o fundo. Fixou fatores de ponderação tendo como referência os anos iniciais do ensino fundamental urbano em 1,00 (100\%). Esses fatores variam entre o menor - Educação Jovens e Adultos 0,80 (80\%) -, 20\% abaixo do valor referência -, e o maior - de 1,30 (130\%) -, $30 \%$ maior que a referência - para um aluno do curso técnico integrado, por exemplo. Por sua vez, o valor mínimo por aluno/ano da Educação Especial possui o valor ponderado de 1,20 (120\%) $-20 \%$ superior ao valor de referência.

Importante notar que o Fundeb, por meio de seus fatores de ponderação, indica-nos que, de acordo com cada segmento da educação básica, é necessário um esforço maior do Estado brasileiro para garantir uma educação de qualidade considerando, principalmente, as especificidades inerentes de cada caso. Em relação à Educação Especial, entendemos que o esforço a ser desenvolvido não deve ser de apenas de $20 \%(1,20)$ a mais, e sim de $140 \%$ $(2,40)$ - maior de esforço e empenho em relação ao segmento referência - séries iniciais do ensino fundamental urbano $(1,00)$.

De toda forma, vale destacar que os fatores de ponderação, apesar das distintas consequências que podem acarretar, sinalizam prioridades em termos de política pública (ARAÚJO, 2013). Analisado dessa perspectiva, indubitavelmente o Fundeb, na forma como está disciplinado, orienta que haja um maior esforço estatal (desprendimento de recursos financeiros) com a modalidade da Educação Especial. Conforme constatam Bueno e Pergher (2017), os fatores de ponderação ao longo do tempo evidenciam que as etapas e modalidades antes depreciadas/esquecidas vêm ganhando destaque na preocupação da política educacional em termo de necessidade de investimentos. Nesse sentido é que, em realidades onde a política econômica tem precedência relativamente às políticas sociais, o aporte de novos recursos tende a acirrar as disputas pelo fundo público, mascarando/inibindo os perceptíveis avanços no ensino aprendizagem nas instituições públicas.

Esses apontamentos subsidiam nossas defesas de que a matrícula do AEE (duplo financiamento), em regra, deve ser na mesma escola da matrícula da escolarização, a fim de que o apoio educacional complementar - seja ele na forma limitada (pequenos períodos; curta duração) ou, em alguns casos, de forma permanente (regular e periódico) - possa ser potencializado, e por consequência os alunos com deficiência possam ter suas potencialidades ao máximo trabalhadas. Além disso, não é demais lembrar que as atividades, os recursos de acessibilidade e pedagógicos devem ser organizados institucionalmente (pela escola do ensino regular), e que o AEE deve integrar a proposta pedagógica da escola, 
Aspectos da Sociodinâmica Público e Privado na Política de Educação Especial no Estado do Espírito Santo

contando com a participação da família, conforme estabelecido no artigo $2^{\circ}$, $\S \S 1^{\circ}$ e $2^{\circ}$ do Decreto $n^{\circ}$ 7.611/2011 (BRASIL, 2011).

Necessariamente, a Educação Especial articula-se com as demais políticas públicas saúde e assistência. No entanto, cabe destacar que cada área tem suas fontes orçamentárias próprias, justamente para não haver confusão orçamentária e não correr o risco de ferir o princípio orçamentário da exatidão, que comprometeria o controle social, a gerência e a programação dos recursos públicos (SANCHES, 2004), pontos sensíveis para o Estado democrático de direito.

Apesar da brecha constitucional outrora citada, o Fundeb definitivamente buscou garantir que a aplicação do dinheiro público ocorresse na escola pública, com a valorização do magistério como premissa. Desse modo, quando o recurso do Fundo é aplicado na escola pública, pelo menos $60 \%$ (sessenta por cento) dos recursos anuais totais dos Fundos são destinados ao pagamento da remuneração dos profissionais do magistério da educação básica (BRASIL, 2007). No entanto, quando há convênio ou contratação do AEE das Instituições Especializadas sem fins lucrativos, o pagamento é efetuado pela parte residual do Fundo (40\%). Todavia, ao gerirem os recursos obtidos, essas Instituições (de natureza privada) não têm o dever de seguir a mesma regra de valorização do magistério público estatal. Em regra, essa política acaba colaborando na iminente precarização do trabalho docente, além de fundamentar a burla à exigência constitucional de concurso público (DI PIETRO, 2015).

Outro ponto relevante nesse debate refere-se à definição da filtragem das matrículas do censo escolar para apropriação dos recursos do Fundeb. Anualmente, a Comissão Intergovernamental de Financiamento para Educação Básica de Qualidade, define, via Nota técnica conjunta SEB/SECADI/SETEC/FNDE, os critérios de filtragem. Entre as diversas possibilidades, cabe destacar que são contabilizadas apenas as matrículas do AEE no mesmo município da escolarização, e que quando há duplo convênio das Instituições Especializadas com estado e município (no Espírito Santo são os contratos a partir de 2014) o valor da matrícula do AEE a ser repassado é destinado ao ente federado que possui a matrícula da escolarização (BRASIL, 2008). Não sem razão, em 2014 a Secretaria de Estado da Educação do Espírito Santo foi categórica ao estabelecer as normas de contratação dos serviços das instituições especializadas.

\footnotetext{
O Estado só arcará com os custos dos alunos público alvo da Educação Especial das redes municipais de ensino dos municípios que assinaram o Convênio de Cooperação Técnica proposto pelo Estado do Espírito Santo, que visa à melhoria das condições de atendimento dos alunos público alvo da Educação Especial (ESPÍRITO SANTO, 2014b, p. 17, grifo nosso).
}

Nesse convênio foi estabelecido que os municípios signatários investissem na ampliação de seu próprio atendimento, apesar de concordarem com a continuidade do fomento do AEE em espaços apartados da rede pública. Essa política aponta mais uma vez para uma "intenção tímida" sobre a primazia do investimento público na escola pública, uma vez que, em tese, os serviços contratados sejam paulatinamente menos demandados.

Feitos esses destaques, a seguir trazemos os dados empíricos gerados pelo modelo de contratação que o estado do Espírito Santo implementou recentemente. No próximo item, trazemos uma comparação das despesas executadas no primeiro ano de vigência desse 
Aspectos da Sociodinâmica Público e Privado na Política de Educação Especial no Estado do Espírito Santo

modelo de contratação dos serviços das instituições privadas especializadas em Educação Especial (2014) e o ano de 2017 - o ano mais recente com dados estatísticos consolidados.

\section{Notas sobre a Educação Especial no Espírito Santo: despesas orçamentárias}

No curso de nossa investigação, levantamos os dados educacionais referentes à matrícula do segmento da Educação Especial nos anos de 2014 e de 2017, tomando como fonte os dados do censo escolar e do Portal da transparência do Espírito Santo, além dos dados de estimativas de matrícula e de receitas do Fundeb coletados e divulgados pelo Instituto Nacional de Estudos e Pesquisas Educacionais Anísio Teixeira (Inep).

Organizamos, portanto, os dados de matrícula do segmento da Educação Especial nos anos de 2014 e de 2017, verificando sua incidência e estabelecendo comparações entre a rede estadual (na sua totalidade), o município de Vitória (capital do estado) e as Instituições Especializadas contratadas pelo estado.

Todos os dados apresentados foram atualizados pelo Índice Nacional de Preços ao Consumidor Amplo (IPCA), calculado pelo Instituto Brasileiro de Geografia e Estatística (IBGE). Essa correção permite comparar os diferentes anos analisados sem as distorções causadas pelo processo inflacionário, corrigindo os valores para preços de dezembro de 2017.

\section{Matrículas e despesas com a Educação Especial em território capixaba nos anos de 2014 e 2017}

A Tabela 1 apresenta o número geral de matrículas de alunos da Educação Especial em escolas de ensino comum no Espírito Santo, o número de matrículas de alunos da Educação Especial na rede municipal de Vitória e na rede estadual, nos anos de 2014 e de 2017.

Tabela 1 - Número de Alunos da Educação Especial no Espírito Santo

\begin{tabular}{|c|c|c|c|c|c|c|c|}
\hline $\mathrm{ANO} \rightarrow$ & \multicolumn{3}{|c|}{2014} & \multicolumn{3}{|c|}{2017} & $\%$ TOTAL \\
\hline Sistema de Ensino $\downarrow$ & E. ESP & AEE & TOTAL & E. ESP & AEE & TOTAL & 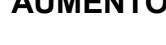 \\
\hline VITÓRIA (Rede Municipal) & 1.111 & 280 & 1.391 & 1.199 & 218 & 1.417 & 1,02 \\
\hline ESTADO (Rede Estadual) & 2.783 & 2.073 & 4.856 & 3.772 & 2.750 & 6.522 & 1,34 \\
\hline GERAL (Estado + Municípios) & 13.112 & 5.754 & 18.866 & 17.930 & 7.950 & 25.880 & 1,37 \\
\hline
\end{tabular}

Fonte: Elaborada pelos autores com base em dados obtidos no site do INEP (2014-2017)

Obs.: Planilha de estimativa da receita anual do Fundeb e coeficientes de distribuição dos recursos - com filtragem conforme portarias Interministeriais de 12/12/2014 e 28/12/2017.

De acordo com os dados da Tabela 1, constata-se que o número de alunos matriculados na Educação Especial (ensino regular + AEE) na rede municipal de Vitória praticamente se manteve em 2014 e em 2017, com um aumento tímido de 2\% (26 alunos) em 2017. No entanto, houve aumento da matrícula no ensino comum e a diminuição da matrícula do AEE.

Já na rede estadual de ensino o número de alunos matriculados na Educação Especial (ensino regular + AEE) teve um aumento considerável de 34\% (1.666), comparando os anos de 2014 e o de 2017 - tendo um aumento de quase 989 matrículas no ensino regular e 677 no AEE. 
Aspectos da Sociodinâmica Público e Privado na Política de Educação Especial no Estado do Espírito Santo

Entretanto, quando colocamos em perspectiva os dados de todo o estado do Espírito Santo (rede estadual + 78 municípios), observamos que, comparativamente, entre os anos de 2014 e de 2017, houve um aumento de 37\% (7.014). No ensino regular (estados e municípios) o aumento chegou a 4.818 matrículas, enquanto o aumento de matrículas no AEE (público e privado) foi de 2.196. Com essas surpreendentes marcas, se parássemos nossa análise por aqui, certamente concluiríamos que o modelo de contratação por esse indicador educacional está sendo um importante propulsor da política pública. Ocorre que esses dados estão agregados, conforme filtragem para repasse do Fundeb, não sendo possível, portanto, saber especificamente o número de matrículas do AEE nas respectivas Instituições Especializadas contratadas pelo governo do estado, o que dificulta acompanharmos as despesas orçamentárias.

Os dados divulgados no Portal da transparência do Espírito Santo ${ }^{6}$ mostram a dinâmica causada pelo credenciamento das Instituições Especializadas no estado. No ano inicial do modelo de contratos tivemos o registro de 65 Instituições Especializadas que, desde então, receberam recursos públicos para oferta do $A E E$, totalizando uma apropriação de $\mathrm{R} \$ 18.937 .181,64$.

Verificamos que, das 63 Instituições Especializadas registradas em 2014, 07 (sete) não prestaram mais serviço para o estado em 2017. Somado a isso, observamos que em 2017 o número de Instituições Especializadas credenciadas caiu para 59. Porém, apesar da descontinuidade de algumas Instituições, outras 03 (três) foram contratadas pelo estado. Percebida essa dinâmica de contratação, os dados revelam ainda que, mesmo com a diminuição do número de Instituições Contratadas em 2014, no ano de 2017 as despesas totalizaram $\mathrm{R} \$ 19.796 .182,88$, evidenciando um aumento de $4,5 \%$ de recursos públicos destinados ao setor privado.

Nesse cenário, indagamos: Por que algumas Instituições Especializadas deixaram de prestar serviço para o estado? Considerando que as Instituições Especializadas não são vinculadas à obrigação de investir $60 \%$ dos recursos em pagamento e valorização do magistério ${ }^{7}$ ? E, notando o aumento expressivo nas matrículas para o AEE privado (chegando a $37 \%$ ), está ocorrendo precarização do trabalho docente nas próprias instituições especializadas, como anunciado por Di Pietro (2015)? Os dados estatísticos que temos e o limite desse artigo não nos permitem responder, por ora, a essas questões. No entanto, não há como não notar a burla da substituição de mão de obra estatal por meio da terceirização e, também, a burla à regra do concurso público ${ }^{8}$ como aspecto importante para a garantia de qualidade social ao trabalho escolar.

A Tabela 2 a seguir, apresenta os dados da única Instituição Especializada localizada em Vitória-ES, justamente para fazermos o exercício de aproximação de nossas lentes de análise.

6 Disponível em: <https://transparencia.es.gov.br/DadosAbertos/BaseDeDados>.

7 Lei n 11.494, de 20 de junho de 2007. Regulamenta o Fundo de Manutenção e Desenvolvimento da Educação Básica e de Valorização dos Profissionais da Educação (BRASIL, 2007).

8 Apesar do considerável número de matrículas, o estado do Espírito Santo nunca realizou um concurso público para a modalidade da Educação Especial, optando e ficando refém de mão de obra contratada. 
Aspectos da Sociodinâmica Público e Privado na Política de Educação Especial no Estado do Espírito Santo

Tabela 2 - Instituição Especializada de Vitória (ES) contratada pelo estado do Espírito Santo

\begin{tabular}{|c|c|c|c|}
\hline \multicolumn{4}{|c|}{ APAE VITORIA } \\
\hline Ano & & & Matrículas AEE em dezembro \\
\hline 2014 & $\mathrm{R} \$$ & $605.562,48$ & 329 \\
\hline 2017 & & $665.679,49$ & 145 \\
\hline
\end{tabular}

Fonte: Elaborada pelos autores com base em dados obtidos no Portal da transparência do Espírito Santo (Dados deflacionados pelo IPCA).

Para a exposição de dados dessa tabela, optamos por utilizar os dados do pagamento referente ao mês de dezembro dos anos de 2014 e 2017 e dividi-los pelo valor de contrato, de $\mathrm{R} \$ 325,77^{9}$. Os dados mostram que, em relação ao mês que adotamos como referência houve uma redução considerável de alunos atendidos, ou seja, se em dezembro de 2014 essa instituição contava com um total de 329 matrículas no AEE, em dezembro de 2017 o número de matrículas foi de 145. Uma hipótese para esse fato advém da não correção do valor do gasto aluno/mês repassado para compra do AEE privado.

Atentemo-nos para o fato de que o valor repassado pelo governo do estado, em 2017 , não teve redução se comparado com o valor repassado em 2014, mesmo com a diminuição do número de matrículas. Isso, de tal sorte, demonstra uma constância na captação de recursos durante o ano letivo, haja vista que o valor é pago pelo estado a partir da presença do aluno, que deve ser confirmada mensalmente. Ou ainda, indica-nos uma "fidelização" da oferta privada, que, a nosso ver, induz o surgimento de estratégias espúrias que podem deixar em segundo plano a premissa do pleno desenvolvimento do educando com deficiência, em prol do sustento financeiro de instituições privadas.

Por fim, esses dados demonstram que o valor do gasto aluno/mês precisa ser divulgado de forma mais acessível. Até mesmo para que a população possa acompanhar (e avaliar) os fins políticos e sociais que justifiquem a contração do AEE privado pelo governo do estado do Espírito Santo (BRA).

Para dirimir as dúvidas relativas ao uso de recursos públicos, consideramos fundamental que o estado divulgue também o detalhamento mensal relativo à quantidade de alunos público-alvo da educação especial que são atendidos no AEE nas escolas públicas estaduais, diferenciando daqueles que optam pelo AEE ofertado em instituições privadas especializadas em Educação Especial, vinculando, nesse caso, a instituição que oferta seus serviços às escolas comuns nas quais os estudantes seguem matriculados. Afinal, sabemos que "[...] a dinâmica escolar não é linear, pois existem alunos que são matriculados durante o percurso, outros trocam de Instituições Especializadas, outros deixam de estudar, entre outros tantos casos" (OLIVEIRA, 2016, p. 125). Por isso, é urgente esse detalhamento no intuito de contribuir para o acompanhamento e o controle social do gasto público.

9 Apesar de estar em contrato a atualização do gasto aluno mensal, o valor pago continua o mesmo, ou seja, desde 2014 não foi corrigido. 
Aspectos da Sociodinâmica Público e Privado na Política de Educação Especial no Estado do Espírito Santo

\section{Considerações Finais e Perspectivas}

O trabalho teve por objetivo problematizar aspectos dos fins políticos e sociais relativos à contratação do $A E E$ privado, feita pelo governo do estado do Espírito Santo (BRA), tomando como base de análise o ano de 2014, início desse modelo, e o ano de 2017. Para tanto, foram apresentadas algumas notas sobre a Educação Especial no Brasil e princípios e conceitos gerais que atravessam o campo da Educação Especial.

Apresentamos os dados das despesas orçamentárias com a contratação do AEE das Instituições Especializadas sem fins lucrativos e cotejamos os dados do ano inicial de vigência do modelo e ano de 2017, por ser o ano mais recente com dados consolidados. Mostramos que no decorrer do período analisado houve um considerável aumento das matrículas da Educação Especial (AEE + ensino regular). Levando em conta todas as redes de ensino, o aumento foi de $37 \%$ (7.014 matrículas) em um período de 4 anos - ou seja, média de 1.753 por ano. Vimos que se algumas instituições deixaram de aderir ao modelo, outras aderiram à proposta em momento oportuno. Os dados revelaram que houve aumento nos repasses, marcando um aumento de $4,5 \%$ de recursos, mesmo que o custo aluno/mês não tivesse sido corrigido. Esse fato mostra claramente que cerca de 20 milhões de reais do fundo público da Educação Especial estão sendo destinados à contratação do AEE da iniciativa privada sem fins lucrativos.

Os dados também mostraram uma situação preocupante, que precisa ser alvo de outras investigações: a precarização do trabalho docente nas instituições especializadas - haja vista não existir a necessidade de vinculação de receita para valorização do magistério na terceirização. Em grande medida, os dados confirmam a burla constitucional ao concurso público (DI PIETRO, 2015) e, além disso, evidenciam a substituição de mão de obra pela via da terceirização, conforme apontamentos da Secont (ESPÍRITO SANTO, 2015).

Entendemos que os fins políticos e sociais das políticas públicas precisam ser mais transparentes e atender ao princípio basilar da administração, que é a publicidade. A esse respeito, o caminho metodológico que percorremos sinaliza que o estado do Espírito Santo necessita avançar na transparência de dados específicos sobre a modalidade da Educação Especial, de forma que possibilitem melhor acesso e compreensão sobre a sociodinâmica entre público e privado, no escopo das políticas públicas em território capixaba. Complementarmente, entendemos que esses dados precisam ser disponibilizados em linguagem acessível, instrumentalizando a população em geral para o acompanhamento e a avaliação do uso dos recursos públicos. Mais exatamente, sugerimos que, da mesma forma como é feito com os dados de matrículas e vagas do/no ensino comum, sejam disponibilizados, mensalmente, os dados sobre as matrículas do AEE das escolas regulares e dos CAEEs, com suas respectivas despesas, no portal da transparência do estado do Espírito Santo.

Para futuras pesquisas, deixamos as seguintes provocações: a privatização do AEE proporciona eficiência e qualidade? Quais as implicações da privatização na Educação Especial no trabalho docente? Na materialização das politicas de Educação Especial, como se delineia o AEE nas instituições privadas, comparativamente ao AEE, no âmbito da escola de ensino comum? Quais desdobramentos políticos o financiamento das Instituições 
Aspectos da Sociodinâmica Público e Privado na Política de Educação Especial no Estado do Espírito Santo

Especializadas traz para o processo de expansão da cobertura da oferta pública nas escolas municipais e estaduais?

Os dados nos provocam a enrijecer as fronteiras entre o público e o privado. Consideramos nocivo o discurso de que a melhor alternativa para expansão da oferta da Educação Especial seja a terceirização do AEE. Por fim, as reflexões desenvolvidas neste texto arregimentam elementos que subsidiam nossa compreensão de que as escolas comuns necessitam construir sua política institucional a partir de saberes e fazeres que emanem da constante reflexão sobre as práticas pedagógicas desenvolvidas nas próprias escolas, especialmente nas atividades que se realizam no AEE. A vinculação entre práticas pedagógicas se constitui como importante dispositivo para a gradativa travessia de uma abordagem especializada, focada na deficiência, para outra mais ampla, que busca responder às condições de ensino e de aprendizagem para todos. Acreditamos que esse processo se consolida com o aporte de recursos públicos na escola pública, com garantia de profissionais estáveis via concurso público, e com uma rede de serviços articulada com atuações intersetoriais que busquem maximizar o desenvolvimento acadêmico e social dos estudantes com deficiência.

\section{Referências}

ADRIÃO, Theresa Maria Freitas. Dimensões e Formas da Privatização da Educação no Brasil: caracterização a partir de mapeamento de produções nacionais e internacionais. Currículo sem Fronteiras, Braga, v. 18, n. 1, p. 8-28, 2018.

ADRIÃO, Theresa Maria Freitas; GARCIA, Teise de Oliveira Guaranha. Educação a domicílio: o mercado bate à sua porta. Retratos da Escola, Brasília, v. 11, n. 21, p. 433, 20 fev. 2018.

APPLE, Michael W. Reestruturação educativa e curricular e as agendas neoliberal e neoconservadora: entrevista com Michael Apple. Currículo sem fronteiras, Braga, v. 1, n. 1, p. 5-33, 2001.

ARAÚJO, Raimundo Luiz Silva. Limites e possibilidades da redução das desigualdades territoriais por meio do financiamento da educação básica. 2013. $401 \mathrm{f}$. Tese (Doutorado em Educação) - Programa de Pós-Graduação em Educação, Área de Concentração: Estado, Sociedade e Educação, Faculdade de Educação, Universidade de São Paulo, São Paulo, 2013.

ARAÚJO, Raimundo Luiz Silva. Estado da arte da relação público e privado na educação básica. FINEDUCA-Revista de Financiamento da Educação, Porto Alegre, v. 5, p. 01-15, 2015.

ARAÚJO, Raimundo Luiz Silva. Apresentação. In: ARAÚJO, Raimundo Luiz Silva; PINTO, José Marcelino (Org.). Público x Privado em tempos de golpe. 1. ed. São Paulo: Fundação Lauro Campos; Fineduca, 2017. p. 8-15.

BALL, Stephen J.; YOUDELL, Deborah. Hidden privatisation in public education. Brussels: Education International, 2008.

BAPTISTA, Claudio Roberto. Ação pedagógica e Educação Especial: a sala de recursos como prioridade na oferta de serviços especializados. Revista Brasileira de Educação Especial, Bauru, v. 17, p. 59-76, 2011. 
Aspectos da Sociodinâmica Público e Privado na Política de Educação Especial no Estado do Espírito Santo

BOROWSKY, Fabíola. O público e o privado na Educação Especial brasileira: primeiros apontamentos. In: SIMPÓSIO BRASILEIRO DE POLÍTICA E ADMINISTRAÇÃO DA EDUCAÇÃO, 26., 2013, Recife. Anais... Recife: ANPAE, 2013. p. 1-15.

BRASIL. Constituição da República Federativa do Brasil de 1988. Diário Oficial da União, Brasília, 05 out. 1988.

BRASIL. Ministério da Educação. Lei no 9.394, de 20 de dezembro de 1996. Estabelece as diretrizes e bases da educação nacional. Diário Oficial da União, Brasília, 23 dez. 1996.

BRASIL. Ministério da Educação. Resolução CNE/CEB n² 2, de 11 de setembro de 2001. Institui Diretrizes Nacionais para a Educação Especial na Educação Básica. Diário Oficial da União, Brasília, 14 set. 2001.

BRASIL. Lei $n^{\circ} 11.494$, de 20 de junho de 2007. Regulamenta o Fundo de Manutenção e Desenvolvimento da Educação Básica e de Valorização dos Profissionais da Educação FUNDEB, de que trata o art. 60 do Ato das Disposições Constitucionais Transitórias; altera a Lei n o 10.195, de 14 de fevereiro de 2001; revoga dispositivos das Leis n os 9.424 , de 24 de dezembro de 1996, 10.880, de 9 de junho de 2004, e 10.845, de 5 de março de 2004; e dá outras providências. Diário Oficial da União, Brasília, DF, 21 jun. 2007. Disponível em: <http://www.planalto.gov.br/ccivil_03/_ato2007-2010/2007/Lei/L11494.htm>. Acesso em: 20 maio 2016.

BRASIL. Política Nacional de Educação Especial na Perspectiva Inclusiva. Brasília: MEC; SEESP, 2008.

BRASIL. Ministério da Educação. Resolução CNE/CEB, n 4 de 02 de outubro de 2009. Institui Diretrizes Operacionais para o Atendimento Educacional Especializado na Educação Básica, modalidade Educação Especial. Diário Oficial da União, Brasília, 05 out. 2009. Disponível em: <http://portal.mec.gov.br/dmdocuments/rceb004_09.pdf>. Acesso em: 10 dez. 2015.

BRASIL. Ministério da Educação. Decreto ${ }^{\circ} 7.611$, de 17 de novembro de 2011. Dispõe sobre a Educação Especial, o atendimento educacional especializado e dá outras providências. Diário Oficial da União, Brasília, DF, 18 nov. 2011.

BRASIL. Ministério da Educação. Nota técnica $n^{\circ} 055$ de 10 de maio de 2013 (MEC/SECADI/DPEE): Orientação à atuação dos Centros de AEE, na perspectiva da educação inclusiva. Brasília: MEC, 2013. Disponível em: <http://www.ppd.mppr.mp.br/ arquivos/File/NOTATECNICAN055CentrosdeAEE.pdf>. Acesso em: 28 jun. 2015.

BUENO, Ederson Nunes; PERGHER, Calinca Jordânia. Analisando a Trajetória dos Fatores de Ponderação Estabelecidos no FUNDEB: 2007-2016. FINEDUCA - Revista de Financiamento da Educação, Porto Alegre, v. 7, p. 01-18, 2017.

BULOS, Uadi Lammêgo. Curso de direito constitucional: revisado e atualizado, de acordo com a Emenda Constitucional n. 83/2014 e os últimos julgados do Supremo Tribunal Federal. São Paulo: Saraiva, 2015.

DI PIETRO, Maria Sylvia Zanella. Parcerias na Administração Pública: concessão, permissão, franquia, terceirização, Parcerias Público-Privadas e outras formas. 10. ed. São Paulo: Atlas, 2015. 
Aspectos da Sociodinâmica Público e Privado na Política de Educação Especial no Estado do Espírito Santo

ELIAS, Norbert. A Sociedade dos Indivíduos. Rio de Janeiro: Zahar, 1994.

ESPÍRITO SANTO. Constituição do Estado do Espírito Santo. Diário do Poder Legislativo, Vitória, 05 out. 1989.

ESPÍRITO SANTO. Resolução CEE/ES n. 2.152/2010. Dispõe sobre a Educação Especial no Sistema Estadual de Ensino do Estado do Espírito Santo. Diário Oficial, Vitória, 26 fev. 2010.

ESPÍRITO SANTO. Edital de Credenciamento $\mathbf{N}^{\circ}$ 001/2014. Dispõe do credenciamento de instituições comunitárias, confessionais ou filantrópicas sem fins lucrativos para atendimento educacional especializado no contraturno do ensino regular aos alunos da rede estadual e municipal que apresentam deficiência e/ou transtornos globais de desenvolvimento, nos Municípios do Estado do Espírito Santo. Vitória, 2014a. Disponível em: <www.apaees.org.br/anexo.phtml/4024>. Acesso em: 25 fev. 2014.

ESPÍRITO SANTO. Resolução CEE/ES No 3.777, de 13 de maio de 2014. Fixa normas para a Educação no Sistema de Ensino do Estado do Espírito Santo, e dá outras providências. Diário Oficial, Vitória, 13 maio 2014b.

ESPÍRITO SANTO. TCEES No 28, DE 26/11/2013: Relatório técnico de análise e avaliação dos procedimentos relativos aos pontos de controle do anexo 11. Espírito Santo: Secretaria de Estado de Controle e Transparência (SECONT), 2015.

FRANÇA, Marileide Gonçalves. Financiamento da Educação Especial: entre complexas tramas e permanentes contradições. In: REUNIÃO NACIONAL DA ASSOCIAÇÃO NACIONAL DE PÓS-GRADUAÇÃO E PESQUISA EM EDUCAÇÃO, 37., 2015, Florianópolis. Anais... Florianópolis: ANPED, 2015.

GARCIA, Rosalba Maria Cardoso. Educação Especial na perspectiva inclusiva: determinantes econômicos e políticos. Comunicações, Piracicaba, v. 23, n. 3, p. 7-26. 2016.

JANNUZZI, Gilberta Martino. Marcas da Educação Especial na História. In: MENDES, Eniceia; ALMEIDA, Maria Amélia (Org.). Educação Especial inclusiva: legados históricos e perspectivas futuras. São Carlos: Marquezine \& Manzini, ABPEE, 2015. p. 27-31.

LANNA JUNIOR, Mário Cléber Martins. História do movimento político das pessoas com deficiência no Brasil. Brasília: Secretaria de Direitos Humanos, Secretaria Nacional de Promoção dos Direitos da Pessoa com Deficiência, 2010.

MAIOR, Izabel Maria Madeira De Loureiro. Movimento político das pessoas com deficiência: reflexões sobre a conquista de direitos. Inclusão Social, Brasília, v. 10, n. 2, p. 28-36, 2017.

MAZZOTTA, Marcos José da Silveira. Educação Especial no Brasil: história e políticas públicas. 6. ed. São Paulo: Cortez, 2011.

MORAES, Valdete Aparecida Veiga. Publicização/privatização da Educação Especial no Paraná - Gestão Requião (2003-2010). In: ENCONTRO DA ASSOCIAÇÃO BRASILEIRA DE PESQUISADORES EM EDUCAÇÃO ESPECIAL, 7., 2011, Londrina. Anais... Londrina, 2011.

NÓVOA, António. O espaço público da educação: imagens, narrativas e dilemas. In: NÓVOA, António. Espaços de Educação, Tempos de Formação. Lisboa: Fundação Calouste Gulbenkian, 2002. p. 237-263. 
Aspectos da Sociodinâmica Público e Privado na Política de Educação Especial no Estado do Espírito Santo

OLIVEIRA, Gildásio Macedo de. Financiamento das instituições especializadas na política de Educação Especial no estado do Espírito Santo (2012-2015). 2016. $144 \mathrm{f}$. Dissertação (Mestrado em Educação) - Programa de Pós-Graduação em Educação, Universidade Federal do Espírito Santo, Vitória, 2016.

PANTALEÃO, Edson Alves; SOBRINHO, Reginaldo Celio. O financiamento da Educação Especial no Estado do Espírito Santo pós LDBEN 9394/96: uma abordagem históricosociológica. In: CONGRESSO BRASILEIRO DE HISTÓRIA DA EDUCAÇÃO: INVENÇÃO, TRADIÇÃO E ESCRITAS DA HISTÓRIA DA EDUCAÇÃO NO BRASIL, 6., 2011, Vitória. Anais... Vitória, 2011. p. 2-212.

PEREIRA, Cléia Demétrio. Política de convênio na oferta de serviços de Educação Especial no município de Braço do Norte - SC. In: SEMINÁRIO ANPED SUL, 9., 2012, Caxias do Sul. Anais... Caxias do Sul, 2012. p. 1-16.

SANCHES, Osvaldo Maldonado. Dicionário de orçamento, planejamento e áreas afins. 2. ed. Brasília: OMS, 2004.

SÃO PAULO. Secretaria dos Direitos da Pessoa com Deficiência. 30 anos do AIPD: Ano Internacional das Pessoas Deficientes 1981-2011. São Paulo: Imprensa Oficial do Estado de São Paulo, 2011.

SOTO, Ana Paula de Oliveira Moraes et al. Financiamento da Educação Especial no Brasil na arena do público e do privado. Poiésis, Tubarão, v. 6, n. 10, p. 359-376, jul./dez. 2012.

VIEGAS, Luciane Torezan; BASSI, Marcos Edgar. A Educação Especial no âmbito da política de fundos no financiamento da educação. Reflexão e ação, Santa Cruz do Sul, v. 17, n. 1, p. 57-83, 2009.

Gildásio Macedo de Oliveira é doutorando em Educação (UFES), linha de pesquisa: Educação Especial e processos inclusivos; Mestre em Educação PPGE/UFES 2015-2016, linha de Pesquisa Diversidade e Práticas Educacionais Inclusivas do Programa e PósGraduação em Educação da Universidade Federal do Espírito Santo.

ORCID: http://orcid.org/0000-0003-2019-6322

E-mail: gildasioo@bol.com.br

Reginaldo Célio Sobrinho é professor associado do Departamento de Educação politica e Sociedade; Líder do grupo de pesquisa Políticas, Gestão e Inclusão Escolar: contextos e processos sociais; (CNPQ). Gestor do termo de cooperação internacional acadêmica e científica entre a UFES - BRA e a Universidad Veracruzana - MEX e gestor do termo de cooperação internacional acadêmica e científica entre a UFES - BRA e a Universidad de Guadalajara - MEX. Docente do quadro permanente do Programa de Pós-Graduação em Educação - PPGE/UFES.

ORCID: http://orcid.org/0000-0002-4209-2391

E-mail: reginaldo.celio@ufes.br 


\section{Editores do volume 10}

Márcia Aparecida Jacomini - Universidade Federal de São Paulo, Brasil

José Marcelino de Rezende Pinto - Universidade de São Paulo, Brasil

\section{Comitê Editorial}

Nalú Farenzena - Universidade Federal do Rio Grande do Sul, Brasil

Juca Gil - Universidade Federal do Rio Grande do Sul, Brasil

Theresa Adrião - Universidade Estadual de Campinas, Brasil

Ângelo Ricardo de Souza - Universidade Federal do Paraná, Brasil

\section{Conselho Editorial}

\section{Alejandro Morduchowicz}

Universidad Pedagógica, Provincia de Buenos Aires, Argentina

Andréa Barbosa Gouveia

Universidade Federal do Paraná, Brasil

Fernanda Saforcada

Universidade de Buenos Aires, Argentina

Jacques Velloso

Universidade de Brasília, Brasil

João Monlevade

Senado Federal, Brasil

Jorge Abrahão de Castro

Instituto de Pesquisa Econômica Aplicada / IPEA, Brasil

Lisete Regina Gomes Arelaro

Universidade de São Paulo, Brasil

Luis Carlos Sales

Universidade Federal do Piauí, Brasil

Luiz de Sousa Junior

Universidade Federal da Paraíba, Brasil

Luiz Fernandes Dourado

Universidade Federal de Goiás, Brasil

Magna França

Universidade Federal do Rio Grande do Norte, Brasil

Marcos Edgar Bassi

Universidade Federal de Santa Catarina, Brasil

Maria Angélica Pedra Minhoto

Universidade Federal de São Paulo, Brasil

Maria Beatriz Luce

Universidade Federal do Rio Grande do Sul, Brasil

Maria Dilnéia Espíndola Fernandes

Universidade Federal de Mato Grosso do Sul, Brasil

Nelson Cardoso do Amaral

Universidade Federal de Goiás, Brasil

Nicholas Davies

Universidade Federal Fluminense, Brasil

Robert E. Verhine

Universidade Federal da Bahia, Brasil

Romualdo Portela de Oliveira Universidade de São Paulo, Brasil

Rosana Gemaque Rolim

Universidade Federal do Pará, Brasil

Rubens Barbosa de Camargo

Universidade de São Paulo, Brasil

Theresa Adrião

Universidade Estadual de Campinas, Brasil

Tristan McCowan

University of London, Reino Unido

Vera Jacob

Universidade Federal do Pará, Brasil

Vera Peroni

Universidade Federal do Rio Grande do Sul, Brasil

Vitor Henrique Paro

Universidade de São Paulo, Brasil

\section{Equipe editorial}

Apoio ao Comitê Editorial: Caio Cabral da Silva

Diagramação, Revisão de português e normalização: Edson Leonel de Oliveira

Revisão de inglês: Ananyr Porto Fajardo

Fineduca - Revista de Financiamento da Educação

Associação Nacional de Pesquisa em

Financiamento da Educação

e-mail: revista.fineduca@gmail.com | site: http://seer.ufrgs.br/fineduca 